\title{
Analysis and Comparison of Power Electronic Converters for Conventional and Toroidal Switched Reluctance Machines
}

\author{
Zipan Nie*, Nigel Schofield* \\ Department of Electrical and Computer Engineering, McMaster University, Hamilton, Canada \\ Email: *niez4@mcmaster.ca, *nigels@mcmaster.ca
}

How to cite this paper: Nie, Z.P. and Schofield, N. (2017) Analysis and Comparison of Power Electronic Converters for Conventional and Toroidal Switched Reluctance Machines. Energy and Power Engineering, 9, 241-259.

https://doi.org/10.4236/epe.2017.94017

Received: February 6, 2017

Accepted: April 23, 2017

Published: April 26, 2017

Copyright ( 92017 by authors and Scientific Research Publishing Inc. This work is licensed under the Creative Commons Attribution International License (CC BY 4.0).

http://creativecommons.org/licenses/by/4.0/

\begin{abstract}
Different power electronic converter topologies are introduced in this paper for both Conventional Switched Reluctance Machine (CSRM) and Toroidal Switched Reluctance Machine (TSRM) drive systems. Their commutation, switch and diode currents, power losses, and efficiencies under over modulation operation are analyzed and compared for converter characteristics study, performance evaluation and topology selection for CSRM and TSRM drive systems. The switch and diode silicon volumes required for each CSRM and TSRM drives are also compared according to their corresponding currents at the equivalent machine torque versus speed operating points.
\end{abstract}

\section{Keywords}

Power Electronic Converter, Conventional Switched Reluctance Machine, Toroidal Switched Reluctance Machine

\section{Introduction}

Electrical machine drive systems are widely used in different applications, e.g. traction systems, industrial drives, and home appliances. So far the maturely developed and widely applied machine drive systems comprise of brushed DC, AC induction, and AC permanent magnet machine drive systems, whose torque generation are mainly via magnetic excitation and supplemented by some reluctance torque in the case of Interior Permanent Magnet Machines (IPM). For reluctance torque based machines, the development, optimization, and public acceptances of Switched Reluctance Machines (SRM) and Synchronous Reluctance Machines (SynRM) fall behind their counterparts. However, these technologies have received much interest in recent years due to the uncertainty in permanent magnet price [1] with researchers quoting application specific advantages in- 
cluding the potential for low total drive system cost, machine structure robustness and simplicity, control reliability and simplicity, high efficiency, high operation speed, and the elimination of permanent magnet materials [2]-[6] etc. For the current SRM drive systems there are some drawbacks in terms of torque density, torque ripple, and acoustic noise [2].

Due to the different torque generation mechanisms, the requirements of machine inverters for SRMs are different to other machine technologies. For this discussion SRM with a conventional winding configuration, as shown in Figure 1 (a), is referred to the conventional switched reluctance machine (CSRM). Although different inverter topologies for CSRM have been proposed [7], the widely used inverter topology is the asymmetric inverter as shown in Figure 1 (b) in which unidirectional phase current is switched through the phase winding.

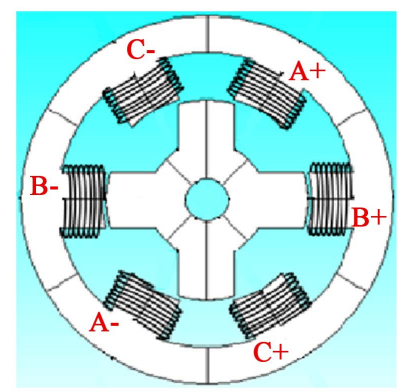

(a)



(b)

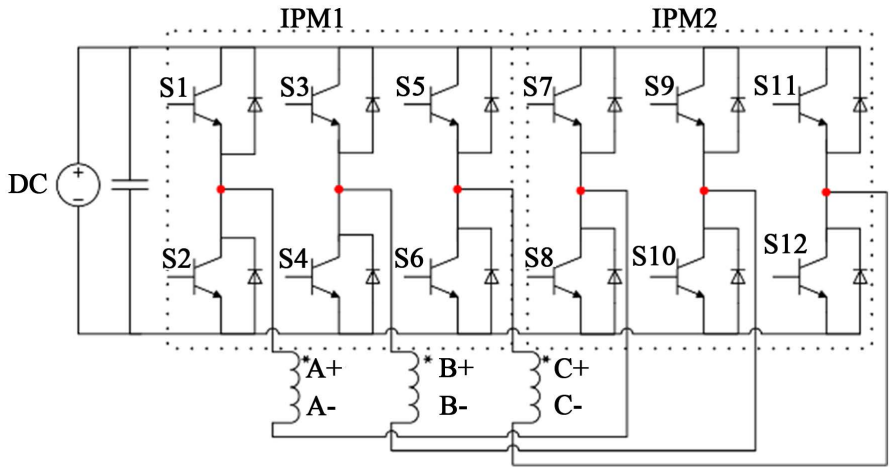

(c)

Figure 1. CSRM and the power electronic converters: (a) CSRM winding configuration; (b) 6 switch mode CSRM power electronic converter; (c) 12 switch mode CSRM power electronic converter. 
The Toroidal Switched Reluctance Machine (TSRM) has a different winding configuration to the CSRM [8] [9] [10], having the stator coils toroidally wound on the stator back iron, as shown in Figure 2(a). Compared with CSRMs this potentially yields better cooling and improved winding packing factor [11]. The different winding configuration of the TSRM leads to its different current paths than the CSRM, requiring different commutations and power electronic converter topology [9] [10] [12]. Different power converter topologies and control strategies have been proposed for CSRM and TSRM [13] [14] [15] [16] as shown in Figure 1 and Figure 2. However, the silicon device specifications required by different CSRM or TSRM drive systems have not been analyzed and compared before.

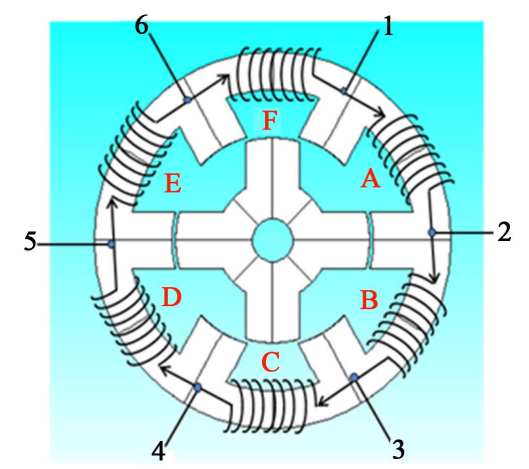

(a)

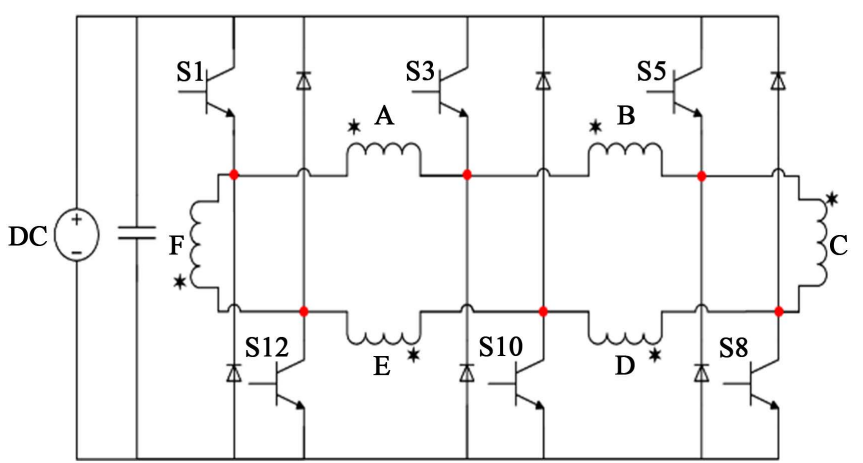

(b)

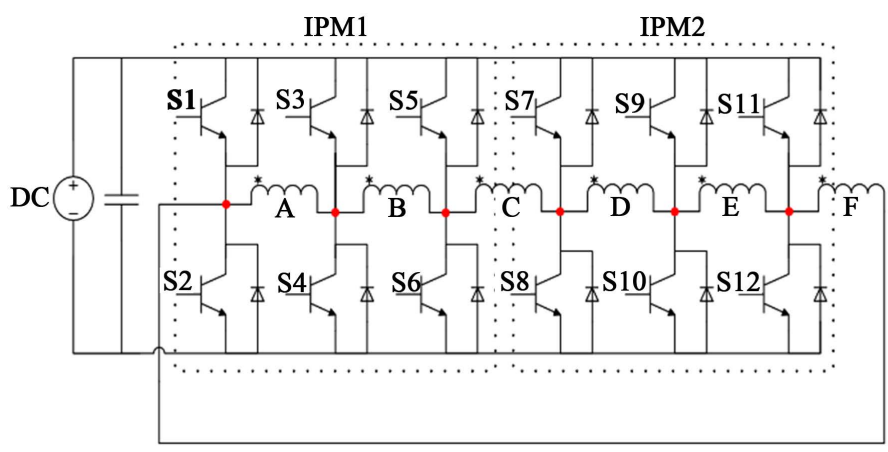

(c)

Figure 2. TSRM and the power electronic converters: (a) TSRM winding configuration; (b) 6 switch mode TSRM power electronic converter; (c) 12 switch mode TSRM power electronic converter. 
This paper presents different power electronic converters for both CSRM and TSRM, their topologies, commutation strategies, switch and diode currents, and power dissipation of silicon devices, which can help to make references when determining the ratings of power electronic switches, diodes and evaluating the converter performance and characteristics. Experimental tests have been conducted under different DC-link voltages and different torque versus speed operating points. Analysis and comparisons have been made for device currents, power losses and efficiencies for the different power converters. The required power electronic silicon material volume is also compared among different converters. The purpose of this research is to suggest the application guideline for the inverter systems for CSRM and TSRM, both 6SW and 12SW mode. What the similarities and differences are, containing the inverter system power losses, efficiencies, power semiconductor ratings, commutation characteristics, etc., and what the attentions should be paid under different application criteria, for example, electric vehicles, home appliances, aerospace applications, etc.

\section{Power Electronic Converters for CSRM and TSRM}

Two different power electronic converters are proposed for either the CSRM shown in Figure 1(a) or TSRM shown in Figure 2(a). The CSRM power converter topologies are illustrated in Figure 1, in which Figure 1(b) shows a typical asymmetric converter, i.e. 6 switch mode $(6 \mathrm{SW})$, and Figure 1(c) shows a converter composed of $2 \mathrm{x} 3$-phase full bridge voltage source inverters that implements a 12 switch mode (12SW). For the latter case, the 12 switch mode inverter is practically implemented via $2 x$ IGBT Intelligent Power Modules (IPMs), IPM1 and IPM2. Figure 2 shows two different power converter topologies driving the TSRM, Figure 2(b) 6 switch mode (6SW), and Figure 2(c) 12 switch mode (12SW), again implemented via 2x IPMs.

The switching sequences for CSRM 6SW and CSRM 12SW are given in Figure 3 and Figure 4 shows TSRM 6SW and TSRM 12SW switching sequences. Taking the CSRM 6SW switching sequence for example, in this 4-pole SR machine there are 4 electrical periods in one mechanical revolution i.e. 1 electrical revolution corresponds 1/4 mechanical revolution, 1/4 REV in Figure 3(a). "Event" means the instantaneous commutation state and the "Coil sequence" indicates the on-state switches shown in Figure 1 and Figure 2 under one commutation state. "Coil current" shows the polarity of the though coil current in the respective commutations. While for CSRM 12SW 1 electrical revolution corresponds 1/2 mechanical revolution and the coil current is bipolar, Figure 3(b). Having the same mechanical and electrical revolution relation (under 6SW and 12SW) with CSRM, both the TSRM 6SW and TSRM 12SW have bipolar current in their coils, Figure 4, while the TSRM 6SW has unbalanced current in coils, different to the other systems.

The coil A current waveforms for two different CSRM converters (6SW and 12SW) are shown in Figure 5(a) and Figure 5(b), where the 6SW converter has unipolar current, but in the $12 \mathrm{SW}$ converter the coil current polarity changes in 


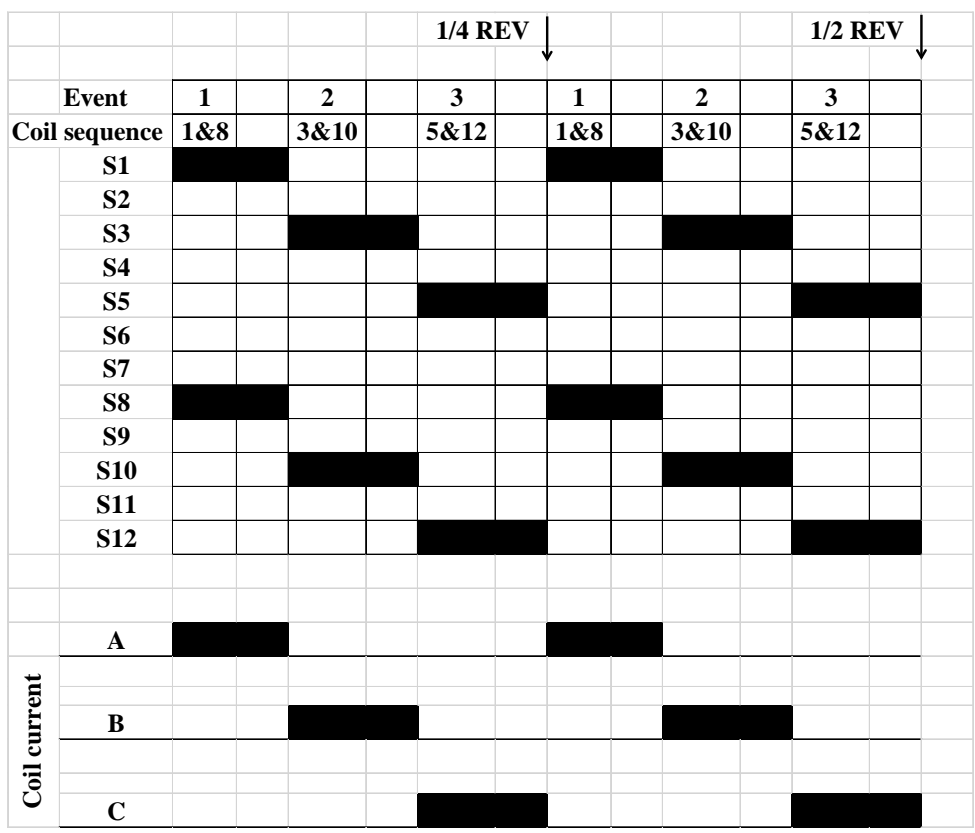

(a)

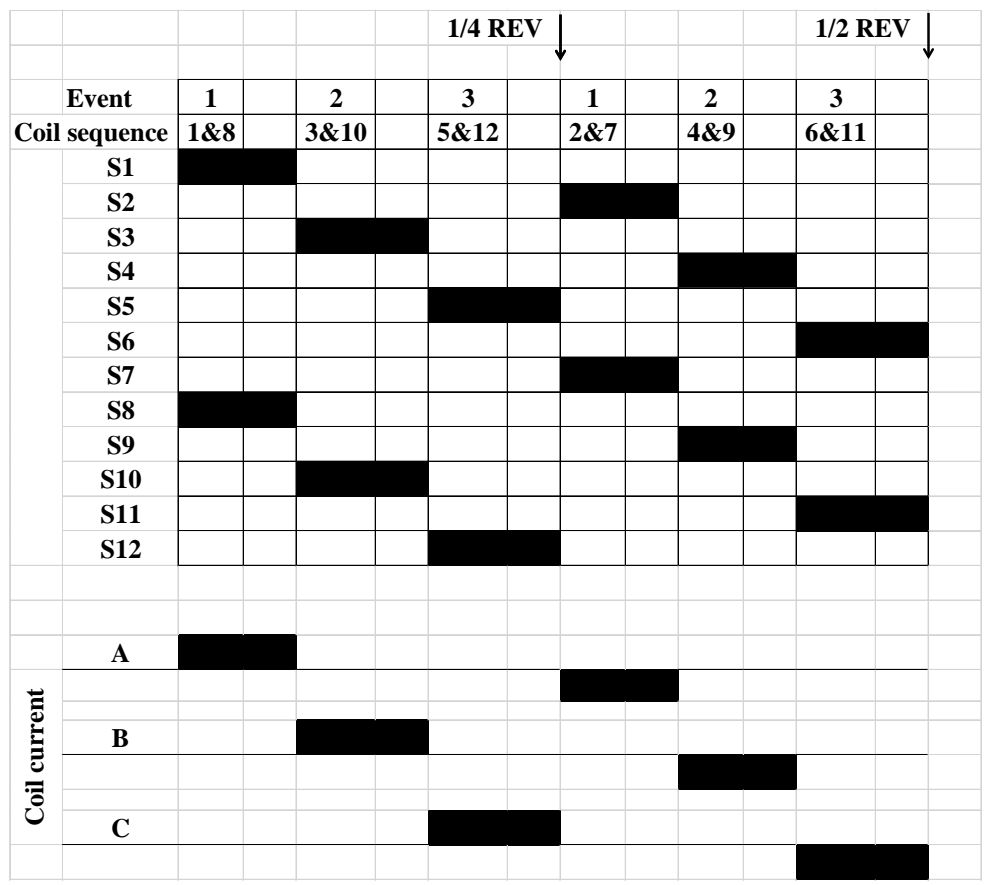

(b)

Figure 3. CSRM switching sequences and corresponding coil current polarity: (a) 6 switch mode CSRM; (b) 12 switch mode CSRM.

every period. During the coil current increasing segment of each pulse, the currents are driven by the DC-link through switches, and during the coil current decreasing segment, the coils are discharged releasing the storage magnetic energy via the diodes. Theoretically, both the converters have the same coil current in spite of their polarity, which means the same overall power dissipation under the same operating conditions. However, in the $12 \mathrm{SW}$ converter the three 




(a)

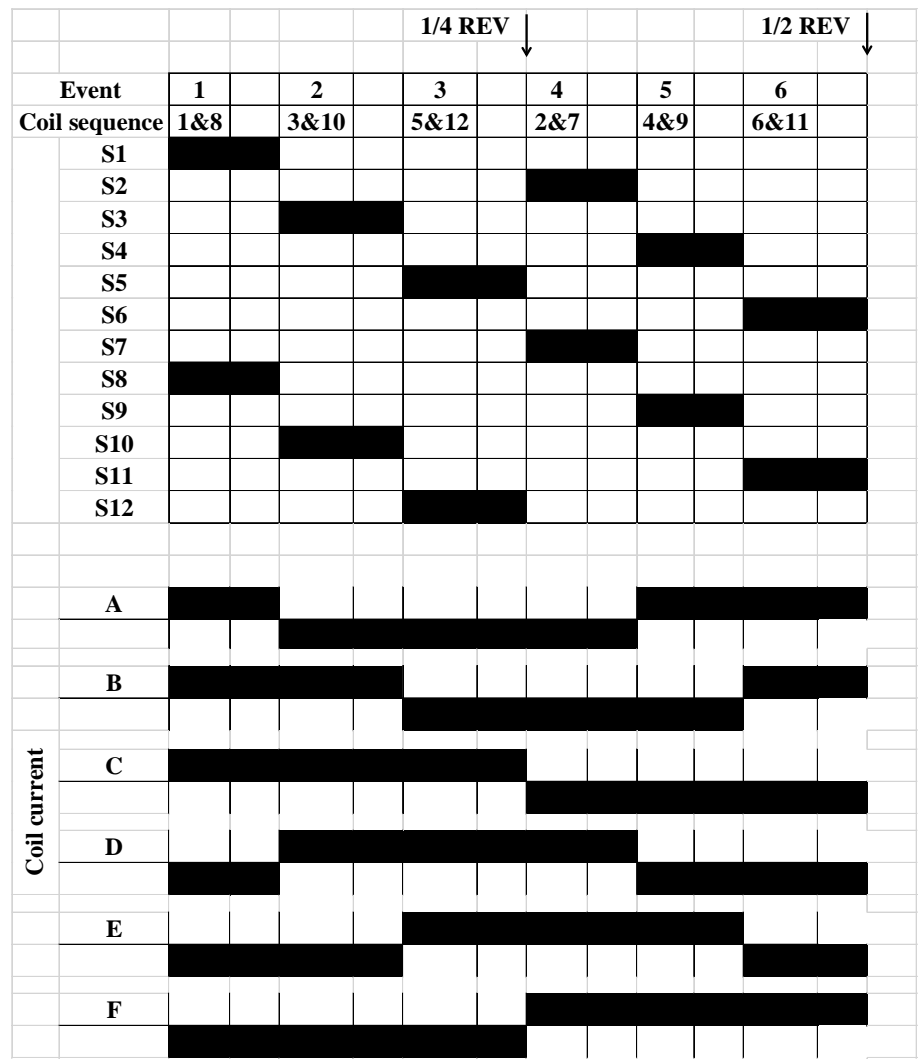

(b)

Figure 4. TSRM switching sequences and corresponding coil current polarity: (a) 6 switch mode TSRM; (b) 12 switch mode TSRM. 


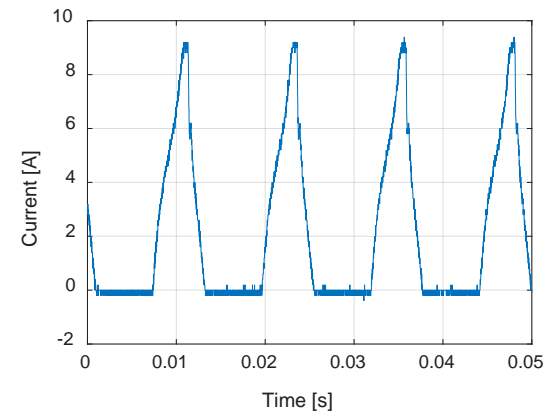

(a)



(b)
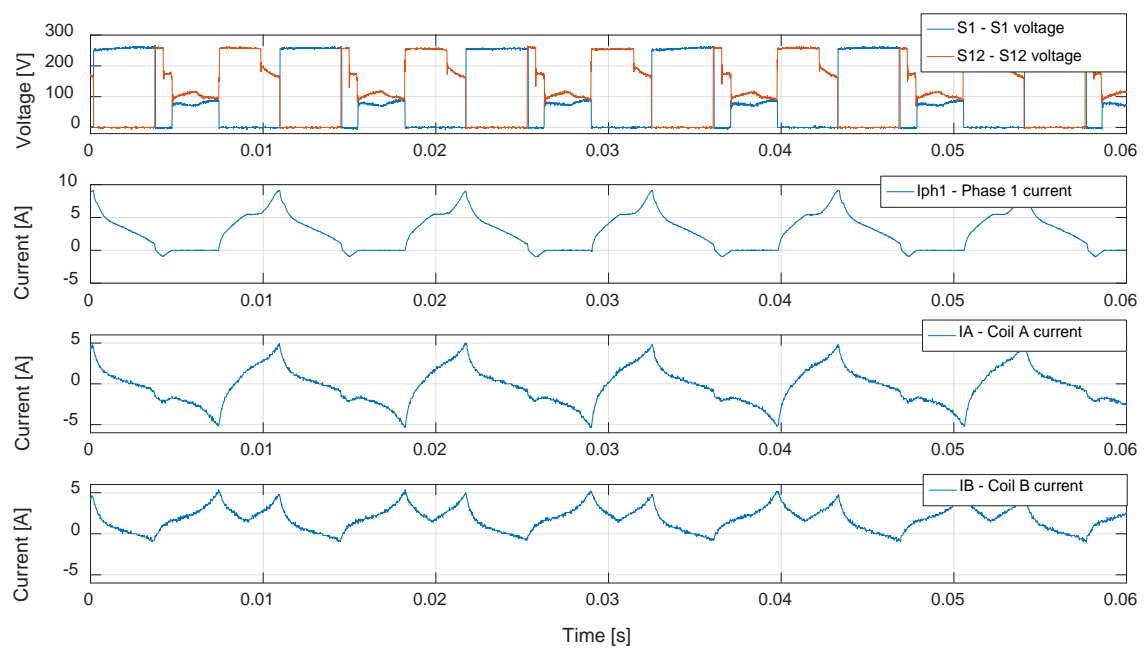

(c)
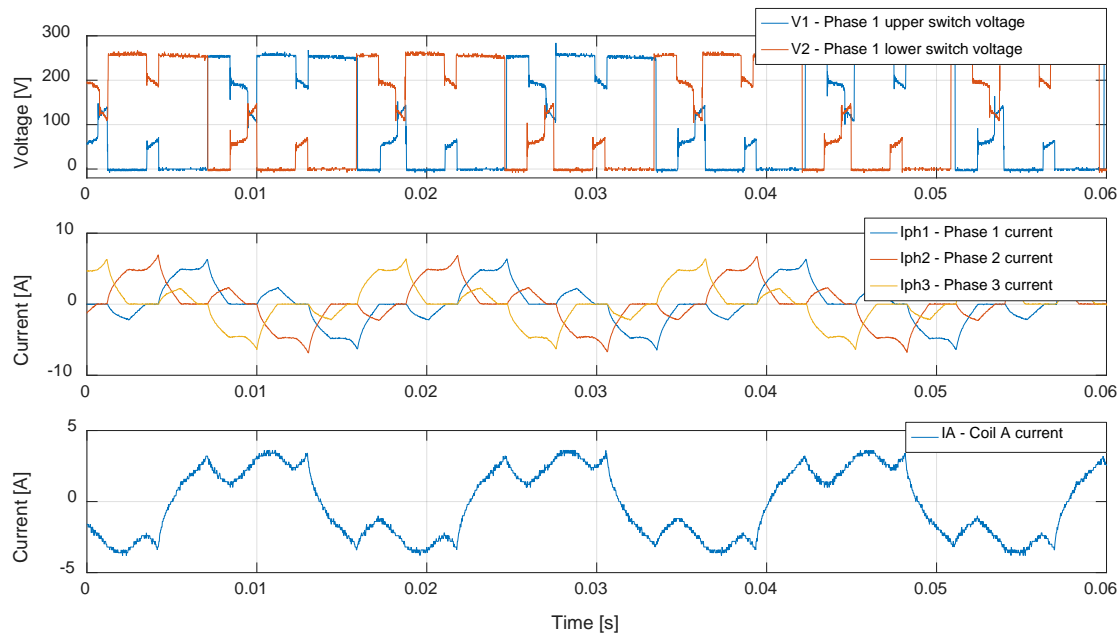

(d)

Figure 5. Experimental current and voltage waveforms for CSRM, TSRM, 6SW and 12SW: (a) CSRM 6SW coil A current; (b) CSRM 12SW coil A current; (c) TSRM 6SW operation waveforms; (d) TSRM 12SW operation waveforms.

coil currents go through 12 switches and diodes, while in 6SW converter currents go through 6 switches and diodes-same overall power dissipation on different numbers of switches and diodes indicating more even and uniform power dissipation on the power silicon cooling surface of $12 \mathrm{SW}$ than $6 \mathrm{SW}$ converter. 
Another characteristics of the CSRM power converters is that their coils are independently connected to the DC bus, which means from the converter side, there is no mutual effects between different phases and the current waveform of each coil can be studied and analyzed separately. That is also called the decoupled characteristics in CSRM while in TSRM the mutual effects among different phases counts. From the machine torque generation view, in terms of CSRM it is the coil self-inductance variation that contributes torque while in TSRM both the self- and mutual- inductances work.

There are two different converter topologies for the TSRM drive system proposed in this paper. Figure 2(b) shows the topology for 6SW TSRM converter, and its current waveforms for different coils and phases are by nature not all the same, as shown in Figure 5(c), resulting in the switches and diodes currents unbalance in the converter that means the ratings and losses among different switches and diodes are not all the same. Also the mutual effects or coupling among neighboring coils, and the diode voltage clamping effects introduce transient voltage states during the switch commutations, which does not exist in CSRM converters. But the switches transient voltages are lower than the DC-link voltage implying the same voltage rating of switches and diodes compared with CSRM converters.

In the 12SW TSRM power electronic converter, Figure 2(c), both the coil currents and phase currents are balanced, which means different coil and phase currents have the same waveform shapes but with certain phase shift among them, as shown in Figure 5(d). Similar with 6SW converter, coupling among phases and hence the switch transient voltage states also exist.

\section{Semiconductor Device Ratings}

The semiconductor device ratings are constrained and determined by their electrical, material, mechanical, and thermal properties, design, and manufacture processes etc., among which the thermal properties are comparatively dominant on the rating restrictions. Thermal properties of a device are determined by its power loss and heat transfer characteristics. Power losses in a semiconductor device include conduction losses, switching losses, diode recovery losses, gate drive losses and blocking losses, which introduce heat generation on device chips. Among these losses blocking losses are normally neglected [17]. Heat transfer characteristics are dependent on the material applied and the switch geometry design.

According to the machine drive system application, Insulated Gate Bipolar Transistors (IGBT) and Metal Oxide Semiconductor Field Effect Transistors (MOSFETs) are widely used currently and hence analyzed in this paper. General losses mechanism and calculation methods are introduced here. While the switches ratings are highly dependent on the machine drive type, switching schemes etc.

During the switch-on state, currents go through switches junctions and dissipate joule heat so that the temperature growth occurs at the junction (account- 
ing for the majority), the internal leads and contacts, and the external connectors. The current through the switch is constrained below some certain value to prevent the thermal breakdown and latch up [18]. Take the IGBT for example; two current restrictions are the maximum continuous collector current and a maximum peak current pulse whose magnitude, width and some other conditions are pre-defined by manufactures [19].

During the off-state, at least one junction is reverse-biased to hold the voltage which has an upper limitation equal to the breakdown voltage of the device junction [18]. That is called maximum rated collector-emitter voltages which is dependent on junction temperatures [19].

The silicon volume used in switch/diode is mainly dependent on the power dissipation and hence the RMS or average currents, maximum rated collector-emitter voltages (the thickness of switch dies), material thermal conductivity, and the switch and diode dies layouts.

\subsection{Conduction Losses}

During the conduction mode, the IGBT switch can be modelled via an equivalent circuit in which a DC voltage source and an on-state resistance are connected in series [19], [20]:

$$
u_{C E}\left(i_{C}\right)=u_{C E 0}+r_{C} \cdot i_{C}
$$

where $u_{C E}$ is the collector-emitter voltage, $u_{C E 0}$ is the modelled DC voltage source, $r_{C}$ is the equivalent on-state resistance, and $i_{C}$ is the collector current.

The IGBT instantaneous conduction loss is [20]:

$$
p_{C I}(t)=u_{C E}(t) \cdot i_{C}(t)=u_{C E 0} \cdot i_{C}(t)+r_{C} \cdot i_{C}^{2}(t)
$$

and hence the IGBT average conduction loss in one switching period is [20]:

$$
P_{C A}=\frac{1}{T_{s w}} \int_{0}^{T s w} p_{C I}(t) d t=u_{C E 0} \cdot I_{c a v}+r_{C} \cdot I_{c r m s}^{2}
$$

where $T_{s w}$ is the switching period, $I_{c a v}$ is the average current during this period and $I_{\text {crms }}$ is the RMS current during the integral period.

The diode conduction losses $P_{C A D}$ can be calculated in the same way. Similarly, the MOSFET conduction loss can be modelled similarly with that of the IGBT, however, for a MOSFET $u_{C E 0}$ is zero [20].

\subsection{Switching Losses and Reverse Recovery Losses}

Switching losses are characterized for IGBTs under worst case operation [19] [20], and similar with MOSFET devices [21]. The turn-on loss is the sum of switch-on energy without the effects from the free-wheeling diode $\left(E_{\text {onTi }}\right)$ and the energy caused by diode reverse recovery $\left(E_{\text {onTrr }}\right)$ [19] [20]. Turn-on switching energy can be calculated from [19] [20] [21]:

$$
E_{\text {on }}=\int_{0}^{t r i+t u}\left(u_{C E}(t) \cdot i_{C}(t)\right) \mathrm{d} t=E_{o n T i}+E_{o n T r r}=U_{D D} \cdot I_{C o n} \cdot \frac{t r i+t f u}{2}+Q_{r r} \cdot U_{D D}
$$


where $U_{D D}$ is the converter supply voltage, $I_{C o n}$ is the on-state collector current, tri is the current rise time, tfu is the voltage fall time, and $Q_{r r}$ is the reverse recovery charge.

Turn-off switching energy is given by [19] [20] [21]:

$$
E_{\text {off }}=\int_{0}^{t r u+t f i}\left(u_{C E}(t) \cdot i_{C}(t)\right) \mathrm{d} t=U_{D D} \cdot I_{\text {Coff }} \cdot \frac{t r u+t f i}{2}
$$

where $I_{\text {Coff }}$ is the off-state collector current, tru is the voltage rise time, and $t f i$ is the current fall-time.

Reverse recovery energy is given by [19] [20] [21]:

$$
E_{\text {rec }}=\int_{0}^{t r i+t f u} u_{D}(t) \cdot i_{F}(t) \mathrm{d} t=\frac{1}{4} \cdot Q_{r r} \cdot U_{D r r}
$$

where $u_{D}$ is the voltage across the diode, $i_{F}$ is the current through the diode, and $U_{D r r}$ is the voltage across the diode during the reverse recovery.

\subsection{Gate Drive Losses}

In MOSFETs and IGBTs the semiconductor layers among gate, drain (collector), and source (emitter) terminals introduce gate to drain (collector) capacitance, gate to source (emitter) capacitance and drain (collector) to source (emitter) capacitance, which determine not only the switching transient but also the gate charge, and hence the gate losses during the turn-on and turn-off transients [22]. Although compared with conduction and switching losses gate drive losses are small, investigation on it is necessary to an integral switching transient study.

The required gate charge increases with the switch current rating and voltage rating, between which current rating is the more decisive factor. Gate driver losses can be calculated by [22]:

$$
P_{\text {gate }}=V_{C C} \cdot Q_{g} \cdot f_{s w}
$$

where $V_{C C}$-Driver supply voltage, $Q_{g}$-Total gate charge to drive the switch, and $f_{S W}$-switching frequency. The driver supply voltage and total gate charge are normally given by the manufacturer.

\subsection{Total Losses}

The total power losses in a semiconductor device contain conduction losses, switching losses, reverse recovery losses and gate drive losses (neglecting the blocking losses):

$$
P_{\text {total }}=P_{C A}+P_{C A D}+\left(E_{\text {on }}+E_{\text {off }}+E_{\text {rec }}+V_{C C} \cdot Q_{g}\right) \cdot f_{\text {sw }}
$$

Among them conduction losses, switching losses, and reverse recovery losses are generated on the switch and diode chip which are fitted in some certain kind of package and adhered on heat sinks forming the heat transfer path for heat releasing. While the gate drive losses mainly occur inside the gate drive chips and does not share the same heat transfer path. When the converter efficiency is analyzed, the gate drive losses are necessarily considered. While gate drive losses do not contribute the junction temperature changes hence it will not be counted 
when converter power circuitry thermal performances and current constraints are evaluated.

\section{Experiment and Results Analysis}

The CSRM and TSRM power electronic converters are implemented with the experimental facility containing an Arduino DUE R3 as the controller, 2 PM50RLA060 integrated power modules (3-phase full-bridges IGBT module) from Powerex and their corresponding driver boards, Powerex BP7B, load dynamometer machine, CSRM and TSRM prototypes, power supplies, torque transducer and accessary circuit boards for logic signal conversion and isolation. In terms of measurements, a Tektronix oscilloscope MDO3024, Metrix differential probe MX 9003, and LEM LA 55-P current transducers are used to capture voltage, current and torque waveforms. The experimental facility is given in Figure 6.

\subsection{Comparison between CSRM 12SW and CSRM 6SW}

Switch and diode current, power losses and converter efficiencies are compared between CSRM 12SW and CSRM 6SW for different load operation points. For the over modulation operation, switching losses and reverse recovery losses can be neglected and only conduction losses are taken into consideration. The power dissipations of switches and diodes are dependent on their corresponding RMS currents and average currents, as defined in Equation (3). A water cooling cold plate is used in the experiment set-up to keep the IGBT module case temperature at $20^{\circ} \mathrm{C}$. Thus it is assumed that the parameters applied in Equation (3) are under the condition of $25^{\circ} \mathrm{C}$ junction temperature.

Figure 7(a) and Figure 7(b) show the torque versus speed characteristics, and the switch and diode RMS currents versus speed for different operating points of the CSRM 6SW and CSRM 12SW drive systems at DC-link voltages of 150 and $300 \mathrm{~V}$.

To normalize the experimental results in Figure $7(\mathrm{a})$ and Figure $7(\mathrm{~b})$, the torque to switch and torque to diode RMS current ratios are calculated and compared quantitatively. Figure 7 (c) and Figure 7 (d) show these ratios versus the machine rotational speed at DC-link voltages of 150 and $300 \mathrm{~V}$.

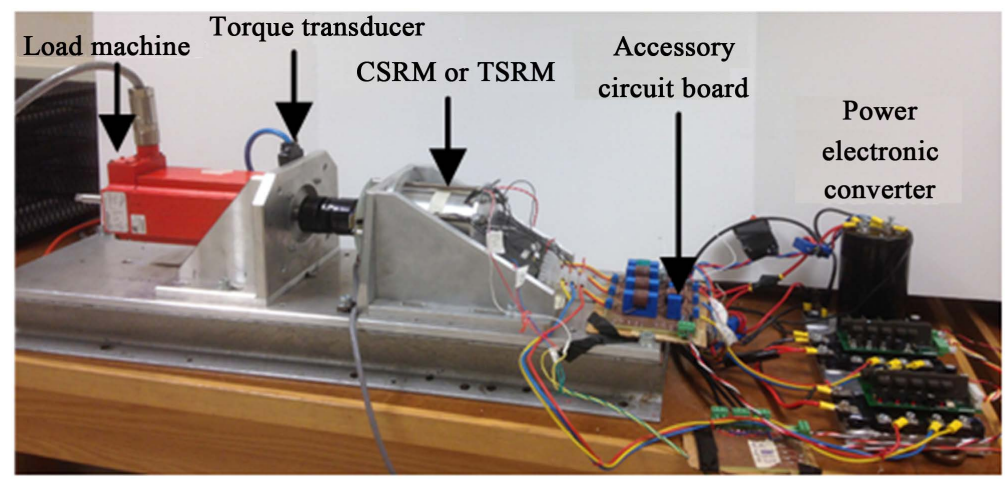

Figure 6. Experimental test facility. 




(a)

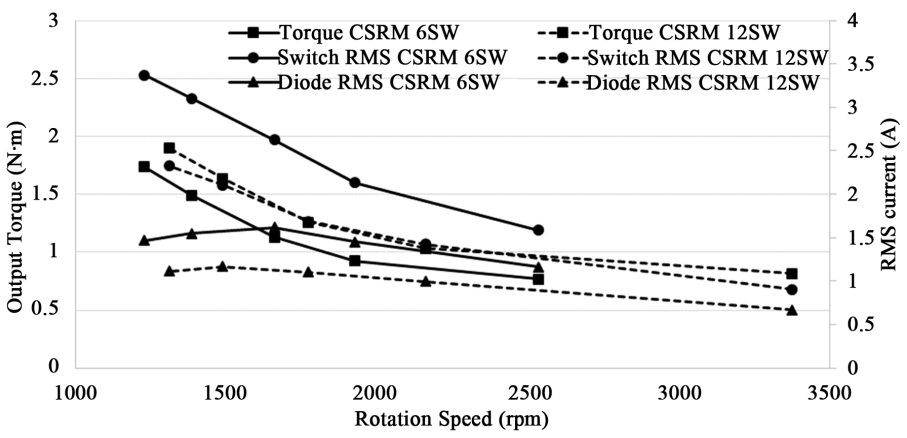

(b)

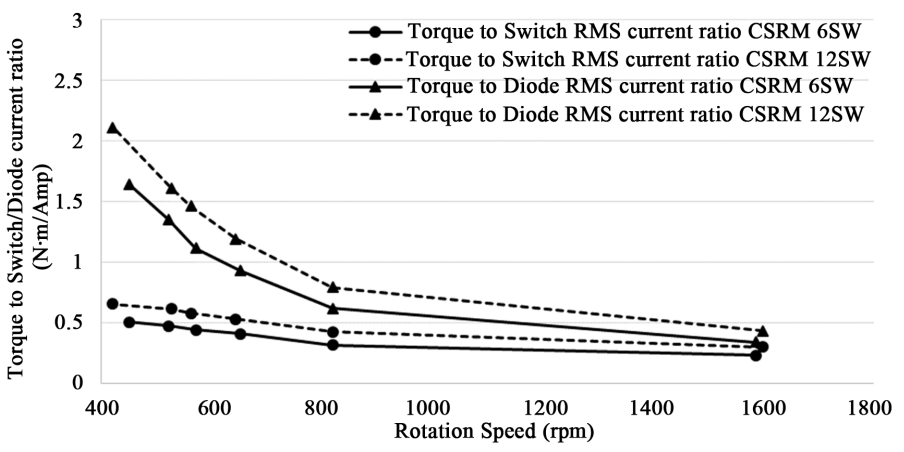

(c)

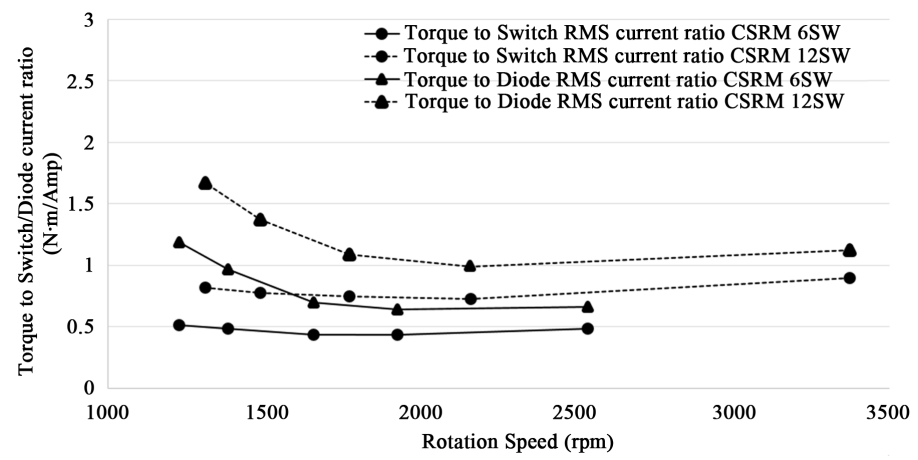

(d)

Figure 7. Experimental test results for the CSRM: (a) Torque, diode and switch RMS current versus rotational speed at a DC bus voltage $=150 \mathrm{~V}$; (b) Torque, diode and switch RMS current versus rotational speed at a DC bus voltage $=300 \mathrm{~V}$; (c) Torque to switch and torque to diode RMS current ratio versus rotational speed at a DC bus voltage $=150$ $\mathrm{V}$; (d) Torque to switch and torque to diode RMS current ratio versus rotational speed at a DC bus voltage $=300 \mathrm{~V}$. 
Figure 7(c) and Figure 7(d) denote higher torque to switch and torque to diode RMS current ratios for the CSRM 12SW converter than the CSRM 6SW converter, which means that to generate the same torque the RMS currents per switch and diode are lower in CSRM 12SW than those in CSRM 6SW. However, these ratios of CSRM 12SW are not simply the twice of those for CSRM 6SW, even the switch and diode numbers in CSRM 12SW doubling those in CSRM $6 \mathrm{SW}$, but vary under different operation points and DC-link voltages. Also in either CSRM 12SW or CSRM 6SW under the same operation point the torque versus diode RMS current ratios are more than the torque versus switch RMS current ratios, which is understandable because the excitation currents via switches are more than the freewheeling currents through diodes as shown in Figure 5(a) and Figure 5(b). In semiconductor devices the switches are normally designed to have the same current and voltage ratings with their respective freewheeling diodes so only the torque versus switch RMS current ratios are investigated and compared for simplification. On the contrary if the equivalent current rating requirement in switch and its freewheeling diode are not considered, for this specific and some other certain applications the freewheeling diodes can be designed with lower current ratings than the corresponding switches to save the silicon materials and hence the costs.

Under the DC-link voltage of $150 \mathrm{~V}$ the difference between the torque versus switch RMS current ratios of both CSRM 12SW and CSRM 6SW is not sound, $0.65 \mathrm{~N} \cdot \mathrm{m} / \mathrm{Amp}$ and $0.5 \mathrm{~N} \cdot \mathrm{m} / \mathrm{Amp}$ at the highest torque points on Figure $7(\mathrm{c})$. While this difference is enlarged when the DC-link voltage becomes $300 \mathrm{~V}$ that the ratios are $0.83 \mathrm{~N} \cdot \mathrm{m} / \mathrm{Amp}$ and $0.5 \mathrm{~N} \cdot \mathrm{m} / \mathrm{Amp}$ at the highest torque points on Figure 7(d). For the torque to diode RMS current ratios of both CSRM 12SW and CSRM 6SW under 300V DC-link voltage, the values are $1.67 \mathrm{~N} \cdot \mathrm{m} / \mathrm{Amp}$ and $1.17 \mathrm{~N} . \mathrm{m} / \mathrm{Amp}$ respectively. Assume that the switch or diode silicon volume required is proportional to the joule heat, hence the square of the RMS current through themselves. Between CSRM 6SW and CSRM 12SW and under the same machine operating point, the former drive system requires 2.79 times silicon volume for each switch and 2.09 times silicon volume for each diode. However, the total switches number of CSRM 6SW is half the CSRM 12SW so that the total switch and diode silicon volume for CSRM 6 SW is 1.39 times and 1.04 times of those for CSRM 12 SW.

From the current waveforms observation in Figure 5(a) and Figure 5(b), the switch conduction segments account for $1 / 3$ of the total period in CSRM 6SW and $1 / 6$ of the total period in CSRM 12SW. The switch RMS currents measured from the test setup are the switch RMS current during the total electrical period, while under the steady state operation the junction temperature hits the peak at the every ends of the switch conduction segments, which means that although the switch RMS currents over the whole electrical period provide a reference for the converter switch RMS current ratings, the switch RMS currents during the every conduction segments should also be considered. However this situation only occurs under low speed that the switching period is compared to the silicon 
junction thermal time constant. Under this situation, the switches and diodes in CSRM 6SW and CSRM 12SW require the same current ratings if the switch and diode RMS currents over the conduction segments are considered although the switches and diodes number in CSRM 12SW doubles that of CSRM 6SW. In this paper the RMS current of the whole electrical period is considered assuming that the machine rotational speed is not low enough hence the switch period is not compared to the silicon junction thermal time constant.

Defined in Equation (3), switch and diode power dissipations are dependent on both RMS current and average current through them. Figure 8 shows the switch and diode average currents during one commutation state. Under similar machine torque versus speed operating points, CSRM 12SW has lower switch and diode average current than CSRM 6SW, approximate the half, which is easy to be understood because CSRM 12SW switch current electrical period doubles that of CSRM 6SW while their conduction segment currents are the same.

Table 1 shows the total power dissipations and their respective efficiencies under different operation points. No significant difference occurs between CSRM 6SW and CSRM 12SW.

Table 1. CSRM 6SW and 12SW power electronic converter power losses and efficiencies at different operating points.

\begin{tabular}{|c|c|c|c|c|}
\hline & Rotational speed (rpm) & DC-bus input power (W) & Power losses (W) & Efficiency (\%) \\
\hline \multirow{6}{*}{$150 \mathrm{~V} 12 \mathrm{SW}$} & 1600.0 & 162.3 & 6.5 & 96 \\
\hline & 819.7 & 247.5 & 9.9 & 96 \\
\hline & 643.8 & 354.0 & 10.9 & 96 \\
\hline & 561.8 & 321.0 & 11.2 & 96 \\
\hline & 526.3 & 276.9 & 12.3 & 95 \\
\hline & 420.2 & 516.0 & 12.1 & 97 \\
\hline \multirow{6}{*}{$150 \mathrm{~V} 6 \mathrm{SW}$} & 1587.3 & 195.9 & 5.8 & 97 \\
\hline & 819.7 & 363.0 & 9.3 & 97 \\
\hline & 652.2 & 399.0 & 10.4 & 97 \\
\hline & 571.4 & 351.0 & 11.1 & 96 \\
\hline & 521.7 & 459.0 & 12.0 & 97 \\
\hline & 449.8 & 444.0 & 12.9 & 97 \\
\hline \multirow{5}{*}{$300 \mathrm{~V} 12 \mathrm{SW}$} & 3372.7 & 192.3 & 6.9 & 96 \\
\hline & 2159.1 & 223.8 & 10.6 & 95 \\
\hline & 1770.4 & 272.4 & 12.0 & 95 \\
\hline & 1485.5 & 318.0 & 14.0 & 95 \\
\hline & 1310.3 & 345.0 & 14.7 & 95 \\
\hline \multirow{5}{*}{$300 \mathrm{~V} 6 \mathrm{SW}$} & 2533.8 & 267.0 & 8.4 & 96 \\
\hline & 1924.3 & 246.3 & 10.9 & 95 \\
\hline & 1657.9 & 408.0 & 12.7 & 96 \\
\hline & 1382.8 & 429.0 & 13.9 & 96 \\
\hline & 1227.2 & 543.0 & 14.6 & 97 \\
\hline
\end{tabular}






(a)

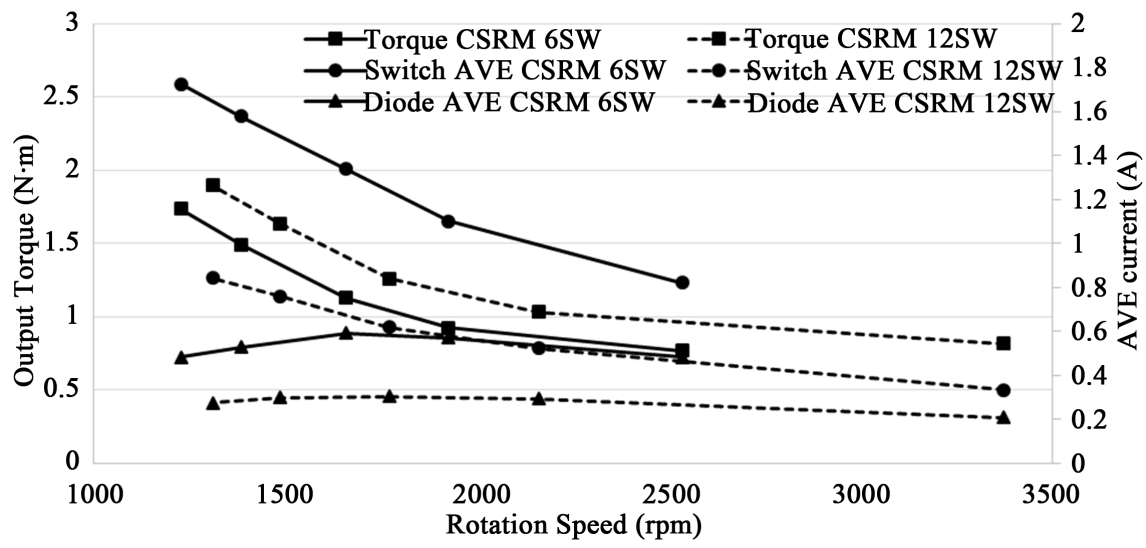

(b)

Figure 8. Test results for torque, diode and switch average (AVE) current versus rotational speed for the CSRM: (a) DC bus voltage $=150 \mathrm{~V}$; (b) DC bus voltage $=300 \mathrm{~V}$.

\subsection{Comparison between TSRM 12SW and CSRM 12SW}

Symmetric characteristics is an advantage of TSRM 12SW over TSRM 6SW and it results in a symmetric design of the power electronic converters (in terms of switch and diode ratings, layout and cooling system design etc.). Consequently, switch and diode current, power losses and converter efficiencies are compared between the TSRM 12SW, the candidate from TSRM family, and CSRM 12SW under different operation points. Similarly, only conduction losses are taken into consideration, and the power dissipations of switches and diodes are dependent on their corresponding RMS currents and average currents.

Figure 9 shows the normalized switch and diode RMS current experimental results, i.e. the torque to switch and the torque to diode RMS current ratios for CSRM 12SW and TSRM 12SW.

When the DC-link voltage is $150 \mathrm{~V}$ there is no significant difference in terms of the torque to switch RMS current, while more diode RMS current is required in CSRM 12SW system. However, when the DC-link voltage is $300 \mathrm{~V}$, the CSRM 12SW system requires less RMS switch and diode currents than TSRM 12SW for equivalent torque output. A higher DC-link voltage is usually selected to have a better power output capability under the same current limitation. When $300 \mathrm{~V}$ 


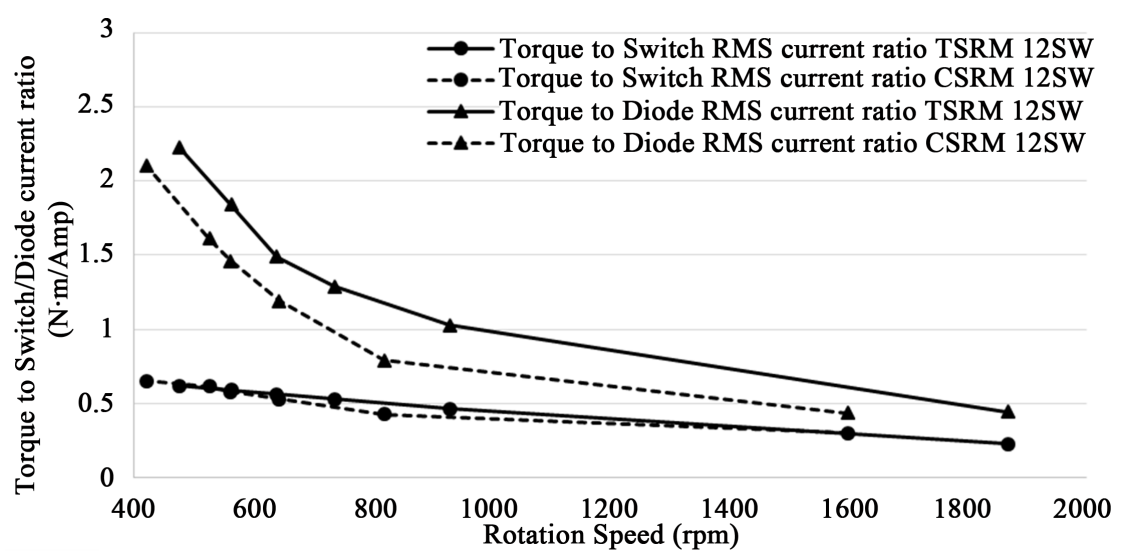

(a)

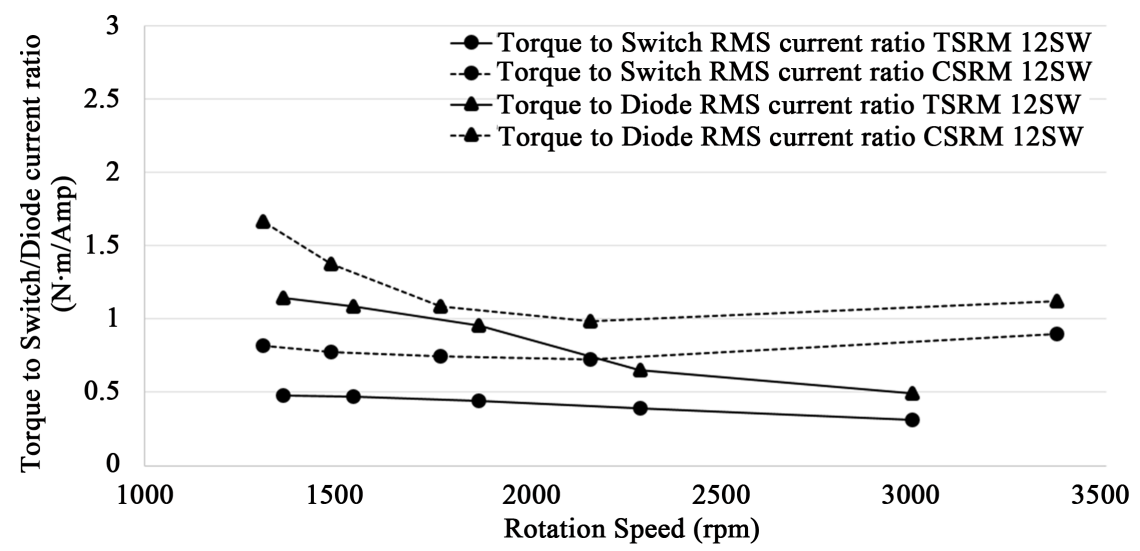

(b)

Figure 9. Test results for torque, diode and switch RMS current ratio versus rotational speed for both the CSRM and TSRM: (a) DC bus voltage $=150 \mathrm{~V}$; (b) DC bus voltage = $300 \mathrm{~V}$.

DC is selected, Figure 9(b), the highest torque points (around 1300rpm) 1.46 times switch RMS current and 1.8 times diode RMS current are required for the TSRM 12SW than those in CSRM 12SW which indicates that more silicon volume is required. Assume that the switch or diode silicon volume required is proportional to the joule heat, hence the square of the RMS current. Comparison between CSRM 12 SW and TSRM 12 SW identifies that to drive the same torque output, TSRM 12SW requires respectively 2.13 times and 3.24 times switch and diode silicon volume compared with CSRM 12SW.

Table 2 shows the total power dissipations and their respective efficiencies under different operating conditions and DC-link voltages for TSRM 12SW. Comparison between TSRM 12SW in Table 2 and CSRM 12SW in Table 1 shows that there is no significant difference in terms of power losses and efficiencies at similar operating conditions.

\section{Conclusion}

Assuming that the CSRM and TSRM have equivalent performance, a comparison is made between the TSRM 12SW, CSRM 12SW and CSRM 6SW (as a bench 
Table 2. TSRM 12SW power electronic converter power losses and efficiencies under different operating points.

\begin{tabular}{|c|c|c|c|c|}
\hline & Rotational speed (rpm) & DC-bus input power (W) & Power losses (W) & Efficiency (\%) \\
\hline \multirow{6}{*}{$150 \mathrm{~V} 12 \mathrm{SW}$} & 1869.2 & 137.1 & 6.7 & 95 \\
\hline & 930.2 & 303.0 & 10.9 & 96 \\
\hline & 736.2 & 408.0 & 12.6 & 96 \\
\hline & 639.0 & 483.0 & 13.9 & 97 \\
\hline & 562.9 & 537.0 & 14.1 & 97 \\
\hline & 475.4 & 636.0 & 15.6 & 97 \\
\hline \multirow{5}{*}{$300 \mathrm{~V} 12 \mathrm{SW}$} & 2997.0 & 163.5 & 9.1 & 94 \\
\hline & 2288.3 & 224.4 & 12.4 & 94 \\
\hline & 1869.2 & 363.0 & 14.5 & 96 \\
\hline & 1544.4 & 507.0 & 16.9 & 96 \\
\hline & 1362.1 & 540.0 & 19.4 & 96 \\
\hline
\end{tabular}

mark) systems based on power electronic loss and operational performances. It has been demonstrated that they have similar total power dissipation and efficiency under similar torque versus speed operating points. While, due to the fact that the switch number in CSRM $12 \mathrm{SW}$ is double that in CSRM 6SW, power losses in CSRM 12SW are more uniformly distributed than those in CSRM 6SW (twice the cooling surface). As a consequence, this leads to a better cooling performance and potentially increases the drive capability. Moreover, the RMS and average currents through each switch and diode in CSRM 12SW are less than those in CSRM 6SW, which also indicates higher drive capability in CSRM $12 \mathrm{SW}$. However, the gate drive number of CSRM 12SW doubles that of CSRM $6 \mathrm{SW}$. The silicon volume required for switches and diodes are also compared between CSRM 6SW and CSRM 12SW converters, and between CSRM 12SW and TSRM 12SW converters.

\section{Acknowledgements}

The authors acknowledge the Canada Excellence Research Chairs (CERC) program, Natural Sciences and Engineering Research Council of Canada (NSERC) Automotive Partnership Canada (APC) for support of Mr. Nie's Ph.D. Studentship.

\section{References}

[1] Kramer, M.J., McCallum, R.W., Anderson, I.A. and Constantinides, S. (2012) Prospects for Non-Rare Earth Permanent Magnets for Traction Motors and Generators. The Journal of the Minerals, Metals \& Materials Society (TMS), 64, 752-763. https://doi.org/10.1007/s11837-012-0351-z

[2] Chau, K.T. (2015) Electric Vehicle Machines and Drives: Design, Analysis and Application. John Wiley \& Sons Ltd., Singapore. https://doi.org/10.1002/9781118752555 
[3] Yang, Y., Schofield, N. and Emadi, A. (2015) Double-Rotor Switched Reluctance Machine (DRSRM). IEEE Transactions on Energy Conversion, 30, 671-680. https://doi.org/10.1109/TEC.2014.2378211

[4] Yang, Y., Schofield, N. and Emadi, A. (2016) Double-Rotor Switched Reluctance Machine Design, Simulations, and Validations. IET Electrical Systems in Transportation, 6, 117-125.

[5] Yang, Y., Schofield, N. and Emadi, A. (2016) Integrated Electromechanical DoubleRotor Compound Hybrid Transmissions for Hybrid Electric Vehicles. IEEE Transactions on Vehicular Technology, 65, 4687-4699.

https://doi.org/10.1109/TVT.2015.2487301

[6] Schofield, N., Long, S.A., Howe, D. and McClelland, M. (2009) Design of a Switched Reluctance Machine for Extended Speed Operation. IEEE Transactions on Industry Applications, 45, 116-122.

[7] Vukosavic, S. and Stefanovic, V.R. (1991) SRM Inverter Topologies: A Comparative Evaluation. IEEE Transactions on Industry Applications, 27, 1034-1047. https://doi.org/10.1109/28.108453

[8] Marlow, R., Schofield, N. and Emadi, A. (2014) A Continuous Toroidal Winding SRM with 6 or 12 Switch DC Converter. 2014 IEEE Energy Conversion Congress and Exposition (ECCE 2014), Pittsburgh, 14-18 September 2014, 3826-3833. https://doi.org/10.1109/ECCE.2014.6953921

[9] Lee, J.Y., Lee, B.K., Sun, T., Hong, J.P. and Lee, W.T. (2006) Dynamic Analysis of Toroidal Winding Switched Reluctance Motor Driven by 6-Switch Converter. IEEE Transactions on Magnetics, 42, 1275-1278.

[10] Lee, J.Y., Lee, B.K., Lee, J.J. and Hong, J.P. (2005) A Comparative Study of Switched Reluctance Motors with Conventional and Toroidal Windings. IEEE International Conference on Electric Machines and Drives, San Antonio, 15-15 May 2005, 1675-1680.

[11] Marlow, R. (2016) Thermal Management for a Switched Reluctance Machine. Ph.D. Thesis, McMaster University, Hamilton.

https://macsphere.mcmaster.ca/bitstream/11375/18721/2/Thesis\%20-\%20R.\%20Ma rlow\%2012-29-15.pdf

[12] Marlow, R., Schofield, N. and Emadi, A. (2015) A Continuous Toroidal Winding SRM with 6- or 12-Switch DC Converter. IEEE Transactions on Industry Applications, 52, 189-198. https://doi.org/10.1109/TIA.2015.2474838

[13] Ye, J., Malysz, P. and Emadi, A. (2014) A Fixed-Switching-Frequency Integral Sliding Mode Current Controller for Switched Reluctance Motor Drives. IEEE Journal of Emerging and Selected Topics in Power Electronics, 3, 381-394.

[14] Neuhaus, C.R., Fuengwarodsakul, N.H. and De Doncker, R.W. (2008) Control Scheme for Switched Reluctance Drives with Minimized Dc-Link Capacitance. IEEE Transactions on Power Electronics, 23, 2557-2564.

https://doi.org/10.1109/TPEL.2008.2002086

[15] Liu, X., Zhu, Z.Q., Hasegawa, M., Pride, A., Deohar, R., Maruyama, T. and Chen, Z. (2011) DC-link Capacitance Requirement and Noise and Vibration Reduction in 6/4 Switched Reluctance Machine with Sinusoidal Bipolar Excitation.2011 IEEE Energy Conversion Congress and Exposition (ECCE 2011), Phoenix, 17-22 September 2011, 1596-1603.

https://doi.org/10.1109/ECCE.2011.6063973

[16] Ye, J., Bilgin, B. and Emadi, A. (2015) An Extended-Speed Low-Ripple Torque Control of Switched Reluctance Motor Drives. IEEE Transactions on Power Electronics, 30, 1457-1470. 
https://doi.org/10.1109/TPEL.2014.2316272

[17] Williams, B.W. (1992) Power Electronics: Devices, Drivers, Applications, and Passive Components. McGraw-Hill, New York.

[18] Mohan, N., Undeland, T.M. and Robbins, W.P. (2002) Power Electronics: Converters, Applications, and Design. 3rd Edition, John Wiley \& Sons, New York

[19] ABB (2013) Applying IGBTs.

https://library.e.abb.com/public/ab119704d4797bc283257cd3002ac5e0/Applying\%2 0IGBTs_5SYA\%202053-04.pdf

[20] Graovac, D. and Pürschel, M. (2009) IGBT Power Losses Calculation Using the Data Sheet Parameters.

[21] Graovac, D., Pürschel, M. and Andreas, K. (2006) MOSFET Power Losses Calculation Using the Data Sheet Parameters.

https://www.element14.com/community/servlet/JiveServlet/download/20553-1-349 3/IGBT\%20Power\%20Losses\%20Calculation\%20using\%20the\%20Data\%20Sheet $\% 2$ 0Parameters.pdf

[22] Hermwille, M. (2007) IGBT Driver Calculation. https://www.semikron.com/dl/service-support/downloads/download/semikron-app lication-note-igbt-driver-calculation-en-2007-10-31-rev-00

Submit or recommend next manuscript to SCIRP and we will provide best service for you:

Accepting pre-submission inquiries through Email, Facebook, LinkedIn, Twitter, etc. A wide selection of journals (inclusive of 9 subjects, more than 200 journals)

Providing 24-hour high-quality service

User-friendly online submission system

Fair and swift peer-review system

Efficient typesetting and proofreading procedure

Display of the result of downloads and visits, as well as the number of cited articles

Maximum dissemination of your research work

Submit your manuscript at: http://papersubmission.scirp.org/

Or contact epe@scirp.org 